\title{
Anger Expression and Risk of Coronary Heart Disease: Evidence From the Nova Scotia Health Survey
}

\author{
Karina W. Davidson, $\mathrm{PhD}^{1}$ and Elizabeth Mostofsky, $\mathrm{MPH}^{2}$ \\ ${ }^{1}$ Department of Medicine, Columbia University Medical Center, New York, NY \\ ${ }^{2}$ Cardiovascular Epidemiology Research Unit, Department of Medicine, Beth Israel Deaconess \\ Medical Center, Harvard Medical School, Boston, MA; Department of Epidemiology, Harvard School \\ of Public Health, Boston, MA.
}

\section{Abstract}

\begin{abstract}
Background-While some studies have found that anger increases the risk of incident coronary heart disease (CHD), others found anger protective. Prior studies did not account for different types of anger expression, which may be associated with opposing levels of cardiovascular risk. This study examines whether distinct types of anger expression differentially predict incident CHD.
\end{abstract}

\begin{abstract}
Methods-We conducted a population-based, observational prospective study of 785 randomly selected Canadian men and women (50\% each) aged 46 to 92 years and free of CHD in 1995. Using videotaped interviews, trained coders rated 3 types of anger expression: constructive anger (discussing anger to resolve the situation), destructive anger justification (blaming others for one's anger), and destructive anger rumination (brooding over an anger-inducing incident). The association between anger expression type per standard deviation and incident CHD was estimated using Cox proportional hazards models adjusted for sex, age cardiovascular risk factors, depressive symptoms, hostility, and anxiety. Interactions of anger expression type and gender were also tested.
\end{abstract}

Results-There were 115 incident CHD events (14.6\%) during 6,584 person-years of follow-up. The association between clinically-assessed constructive anger expression and CHD varied by gender ( $\mathrm{p}$ for interaction $=0.02$ ); higher levels were associated with a lower risk of incident CHD in men only (hazard ratio[HR], $0.58 ; 95 \%$ confidence interval [CI], $0.43-0.80 ; P<.001$ ) whereas higher levels of destructive anger justification was associated with a $31 \%$ increased risk of CHD in both sexes (HR 1.31; 95\% CI, 1.03-1.67; $P=.03$ ) predicted CHD incidence independent of covariates and depressive symptoms, hostility, and anxiety.

Conclusion-Decreased constructive anger in men and increased destructive anger justification in men and women are associated with increased risk of 10-year incident CHD.

Studies on anger expression and incident coronary heart disease (CHD) have not been consistent. 1 For instance, Eng et al2 found that moderate anger expression seemed to protect against incident myocardial infarction and stroke in men participating in the Health Professionals Study, while Chang et al3 found that increased levels of angry reactions to stress

\footnotetext{
(C) 2009 Mosby, Inc. All rights reserved.

Correspondence: Karina W. Davidson, PhD, Department of Medicine, Columbia University College of Physicians and Surgeons, Room 948, PH9 Center, 622 W 168th St, New York, NY 10032 (kd2124@columbia.edu); phone: 212-342-4493; fax: 212-342-3431..

Conflict of Interest: We have no conflicts to report.

Publisher's Disclaimer: This is a PDF file of an unedited manuscript that has been accepted for publication. As a service to our customers we are providing this early version of the manuscript. The manuscript will undergo copyediting, typesetting, and review of the resulting proof before it is published in its final citable form. Please note that during the production process errors may be discovered which could affect the content, and all legal disclaimers that apply to the journal pertain.
} 
(expressed or concealed anger, gripe sessions, and irritability) were strongly associated with premature CHD and premature myocardial infarction in men, and there was no significant association between self-reported measures of anger expression and incident CHD in the Framingham Offspring Study.4 Based on these discrepant findings, some researchers have concluded that anger expression is not a clinically relevant risk factor for CHD.1, 5-7 However, we hypothesized that the conflicting findings may be due to differences in measures of anger expression.

There are at least 3 distinct types of anger expression. ${ }^{8}$ Whereas one type of anger expression can be motivated by constructive reasons - to solve the problem-other types can be motivated by destructive reasons - to justify one's current feelings or to intensify one's anger. ${ }^{9}$ Current self-report measures do not differentiate these types of anger expression. Furthermore, most measures rely on self-reported anger expression rather than a clinical assessment that may provide a more accurate portrayal of the motivation underlying the anger expression. For instance, one study has shown that while a friend, family, and observer may report that an individual expresses destructive anger justification and rumination, that individual usually reports that their anger is primarily constructive. ${ }^{24}$ As a result, the findings on the association between self-reported anger expression and CHD have been inconsistent, ${ }^{1,7}$ with relative risks ranging from insignificant to 6.40 for fatal and nonfatal myocardial infarction, ${ }^{1}$ possibly due to combining measures of harmful and protective aspects of anger expression. Anger expression is also likely to be correlated with other negative emotions, so it is important to examine their simultaneous impact in multivariate analyses, yet such data are rarely available. ${ }^{1}$ This analysis examines the independent role of 3 types of anger expression that were clinically assessed and examined in multivariable analyses accounting for other psychosocial factors in a randomly selected, population-based sample of adult men and women enrolled in the 1995 Nova Scotia Health Survey.

\section{METHODS STUDY POPULATION}

The 1995 Nova Scotia Health Survey10 is a population-based survey implemented by Heart Health Nova Scotia, part of the Canadian Heart Health Initiative cardiovascular disease prevention program, in partnership with the Nova Scotia Department of Health. Statistics Canada, the national statistical agency and census bureau, designed the population-based sampling scheme so that it would be representative of the Nova Scotian population by age, sex, and geographic location. The original targeted population, enrolled from March through November 1995, consisted of all non-institutionalized Nova Scotians aged 18 years and older whose names were listed in the Medical Service Insurance register, the government-sponsored universal health insurance plan. We restricted our sample to those older than 45 years, We restricted our sample to those older than 45 years, as incident CHD at earlier ages likely has different pathophysiologic mechanisms than occur in those over 45 years of age. Additionally, we restricted our sample to those who had attended the clinic session, and those participants without hospital discharge diagnoses of CHD in the 5 years prior to the baseline survey, determined by International Classification of Diseases, Ninth Revision,11(ICD-9) codes 410.x (acute myocardial infarction), 411.x (Other acute forms of ischemic heart disease),413.x (angina pectoris), 414.x (other forms of chronic ischemic disease) or International Statistical Classification of Diseases, 10th Revision, ${ }^{12}$ (ICD-10) codes I21 (acute myocardial infarction), I23 (complications following acute ischemic disease), I24 (other acute ischemic heart diseases), and I25 (chronic ischemic heart disease) in the electronic databases described below. Those with other forms of cardiovascular disease (eg peripheral vascular disease) remained in the sample. 
The overall recruitment rate (72\%) is comparable to those of other large health surveys, and weights applied from propensity analyses to test for response bias revealed no meaningful biases. ${ }^{13}$ Pregnant women were excluded from the survey, as their CHD risk factors (eg, weight, blood pressure, diabetes, etc) were not considered stable at entry.

\section{NOVA SCOTIA HEALTH SURVEY}

A group of 29 public health nurses attended a 5-day training session to learn how to contact participants and conduct the survey in a standardized manner. The nurses contacted the identified residents from March through November 1995, and immediately interviewed those who agreed to participate The survey questionnaire included questions about medical history, lifestyle factors, and standard psychosocial instruments, requiring on average 1.5 hours to complete. Participants were asked to attend a health care clinic for assessment of height and weight and to provide a fasting blood sample for lipid determination. During the clinic visit, the trained interviewers conducted the Expanded Structured Interview, ${ }^{14}$ which was videotaped and subsequently scored for different forms of anger expression. ${ }^{8}$ Completed surveys, clinic measures, and videotaped interviews were sent to the central collection site for double data entry, quality assessment, and statistical analysis. Further details of the study protocol have been described in previous publications. ${ }^{10,15}$

Participants provided written consent to link their health care utilization data and to store and use videotaped interviews, with the understanding that institutional review board approval at the appropriate institution(s) would be sought before any additional analyses would be conducted. Institutional review board approval was originally obtained for the baseline protocol and was subsequently obtained for these analyses at Dalhousie University, Halifax, Nova Scotia, and Columbia University, New York, NY.

\section{COVARIATES}

We selected the Framingham risk components ${ }^{16}$ as covariates to estimate the 10 -year risk of CHD. Participants reported their age and sex. Nurses measured weight and height twice and reported the average of the 2 measurements for each. The averaged values were used to calculate body mass index (calculated as weight in kilograms divided by height in meters squared). Participants also reported if a physician had ever diagnosed them as having diabetes mellitus. Registered nurses measured resting systolic and diastolic blood pressure using a manual random-zero sphygmomanometer. A registered nurse measured systolic and diastolic blood pressure twice during the home visit and twice during the clinic visit. The details and reliability of this measurement has been published previously ${ }^{28}$ Total cholesterol and highdensity lipoprotein cholesterol levels were assayed from plasma samples by the Lipid Research Laboratory, University of Toronto, Toronto, Ontario.17 Low-density lipoprotein cholesterol levels were calculated using the formula reported by Friedewald et al.18 Those who reported smoking in the last year or smoking at the time of the survey were categorized as smokers; the remaining participants were categorized as nonsmokers.

\section{NEGATIVE EMOTIONS}

Levels of depressive and anxious symptoms and hostility were examined with the following self-report measures.

- Centers for Epidemiological Studies-Depressive symptom Scale: This 20-item selfreport instrument was designed for use in epidemiological studies as a measure of current level of depressive symptoms. ${ }^{19}$

- Trait Subscale of the State-Trait Anxiety Scale: This 20-item self-report measure assesses symptoms of anxiety (eg, "I worry too much over something that really 
doesn't matter"). Respondents indicate how they typically experience anxiety symptoms using a 4-point Likert scale. ${ }^{20}$

- Cook-Medley Hostility Scale: This 50-item measure is commonly used to assess self-reported hostility ${ }^{21,22}$ and has been shown to have convergent and discriminant validity and to predict health outcomes. ${ }^{23}$

\section{ANGER EXPRESSION}

The Expanded Structured Interview is a 12-minute stressful interview designed to assess anger expression by asking participants about their characteristic responses to a variety of different situations. ${ }^{14}$ This measure has been previously validated. ${ }^{8}$ Trained nurses conducted the videotaped interviews at the health clinic visit. Trained reviewers coded whether the interview was conducted in compliance with the study protocol, and those interviews that met the quality assurance requirements were scored for the 3 scales of anger expression. To ensure high levels if inter-rater reliability, each coder rated 30 sample tapes that were interspersed among the participants' videos. The results were compared for all coders and three coders were found to have results that were not reliable with the other raters, so their results for participant videos were removed and reanalyzed by one of the 20 coders found to provide reliable results. ${ }^{8}$

The trained anger expression coders watched the recorded interviews to complete the 3 subscales of the Anger Behavior Scale.8, 24 This measure includes 23 items rated on a 4-point Likert rating scale ranging from 1 (almost never) to 4 (almost always). Coders listen to the participant's descriptions of the ways that person typically responds to anger-provoking situations, and they observe the participant's interpersonal behavior during the interview. The items form 3 subscales that were developed and tested extensively ${ }^{8}$ to reflect differing forms of anger expression.

- Constructive Anger Expression: Twelve items assess an individual's use of a constructive, goal-oriented, problem-solving method of anger expression. High scores of constructive anger expression reflect the subjects' ability to deal directly and assertively with the person with whom they are angry, discuss why they feel upset, and resolve the anger situation, in part, by understanding the other person's point of view. People with high scores on constructive anger expression also seek other persons with whom to discuss their anger as they strive to achieve a new way of perceiving and dealing with the anger situation. 25, 26

- Destructive Anger Justification: Six items are used to assess an individual's selfjustification or vindication and attribution of blame elsewhere in an anger-eliciting situation. High scores reflect subjects' need to express anger to defend their opinion and excuse themselves from blame.

- Destructive Anger Rumination: Five items assess the tendency to brood when angry. High scores indicate that subjects hold grudges and discuss anger perseveratively and that their feelings of anger increase over time, reinforcing and intensifying animosity toward the source of the anger. ${ }^{27}$

\section{FOLLOW-UP FOR INCIDENT CHD EVENTS}

The main outcome variable was discharge documentation of incidence of nonfatal or fatal CHD determined by hospital discharge codes (ICD-9, ${ }^{11}$ codes 410.x,411.x, 413.x, and 414.x) and ICD-10,12 codes I21.x, I23.x, I24.x, and I25.x). Because of the universal health care insurance system in Nova Scotia, data from the provincial health care database provide accurate documentation for hospitalizations and outpatient visits of all residents, regardless of event or treatment location. ${ }^{28}$ Physicians submit ICD ${ }^{11} 12$ codes immediately upon discharge, and then a data quality committee from the Department of Health of Nova Scotia meets regularly with 
health records personnel to ensure accuracy, conduct random chart reviews, and to adjudicate discrepancies in data entry. All deaths are reported to provincial offices, which in turn notify the national census bureau, Statistics Canada, which applies a nationally consistent process of determining the underlying cause of death. Specifically, these data were converted to the ICD codes by staff at Statistics Canada, and only those codes listed above qualified as fatal CHD. Data was extracted by Population Health Unit of Dalhousie University.

Participants were observed for up to ten years, (range 0-10 years, median=9.7 years) from the date of their initial visit in 1995 until the earliest of the following: 10-year anniversary of their initial visit date, or March, 2005, or date of emigration, death from causes other than CHD, or documented incident CHD.

\section{STATISTICAL ANALYSIS}

The primary aim was to examine the association between each of the 3 types of anger expression and the risk of incident CHD. Baseline characteristics are presented for the sample, with frequencies and proportions for categorical variables and with means and standard deviations for continuous variables for 3 levels of constructive anger and destructive anger justification. Values for the 73 participants with missing values of systolic and diastolic blood pressure were imputed using Markov chain Monte Carlo multiple imputations. ${ }^{29}$ Consistency estimates (Cronbach $\alpha$ ) are reported for the emotion and expression measures. To determine whether any one coder was unreliable, we calculated the correlation between each coders' ratings and the average of the other coders' ratings (corrected item-total correlation). ${ }^{30} \mathrm{We}$ constructed Cox proportional hazards models and $95 \%$ confidence intervals to estimate the association between each type of anger expression and incident CHD. We allowed the baseline rate of disease to vary by region.

The first model included covariates for sex, age, systolic blood pressure, ratio of total cholesterol to high-density lipoprotein cholesterol, cigarette smoking in the past year, and diabetes mellitus status at baseline. A second model was further adjusted for other psychosocial predictors. We tested the significance of quadratic terms included in the multivariate model to examine whether there was a nonlinear association. Based on previous research, we decided a priori to test for statistical interaction between each of the three types of anger expression and between each anger expression type and gender by testing the statistical significance of the appropriate interaction terms. For any measure with a significant interaction, we tested whether the association between the anger construct and the other negative emotions was present using linear regression models with interaction terms. We verified the proportional hazards assumption by including product terms of the predictors and the log of survival time, and we found no significant violations. All analyses were performed using SAS statistical software (version 9.2; SAS Institute Inc, Cary, NC).

\section{RESULTS}

Table 1 shows the baseline characteristics of the 785 adults over the age of 45 years, with no known cardiovascular disease at baseline who completed the survey and structured interview, by levels of constructive anger and destructive anger justification. Those with low constructive anger scores reported more depressive symptoms and were more likely to smoke. Those with high destructive anger justification were younger, more likely to have diabetes mellitus and to smoke and they had higher levels of hostility.

The Cronbach $\alpha$ values and other characteristics of the emotion scales are reported for this population-based sample (Table 2). The pairwise correlations between the emotion measures (Table 3) indicate that the self-reported emotions are strongly intercorrelated, but were correlated only moderately with the 3 anger expression measures, which in turn were 
moderately correlated with each other. The coder reliability among pairs of coders was .67. No single coder appeared to be an outlier when examining the corrected item-total correlations.

There were 115 incident CHD events (108 nonfatal and 7 fatal; 14.6\%) during the 6584 personyears of observation (17.5 events/1000 person-years). Follow-up ranged from less than 1 to 10.0 years, with an average of 8.4 years. Demographic and predictor variables did not predict length of observed follow-up, but did predict time to events. There was a $31 \%$ increased risk of CHD with each increase of one standard deviation in Destructive anger justification $(P=$. 03; Table 4). The association between Constructive anger and CHD varied by gender ( $\mathrm{p}$ for interaction $=0.02$ ). Among men, an increase of one standard deviation in scores for constructive anger was associated with a $41 \%$ lower rate of CHD (adjusted hazard ratio $=0.59(95 \% \mathrm{CI}$ 0.43-0.80), but there was no statistically significant association between constructive anger and CHD in women. Figure 1 compares the direction and magnitude of our findings with the results of previous studies. Unlike previous studies, our analyses suggest that depressive symptoms remained an independent predictor of incident CHD, adjusting for cardiovascular risk factors, anxiety and hostility.

\section{COMMENT}

In our randomly selected, population-based sample, constructive anger expression was associated with a lower rate of incident CHD, statistically significantly in men only, whereas destructive anger justification was associated with an increased rate of incident CHD over 10 years of follow-up. Many studies have examined the association between anger and cardiovascular disease incidence and progression. However, studies have reported conflicting findings, leading to conclusions that the association between anger or hostility and CHD is difficult to identify or is clinically irrelevant. ${ }^{1,5-7}$ Previous studies examining the association between anger and CHD have often relied on measures that combine the subtypes of protective and harmful anger expression, and may have suffered from inaccuracies of self-report measures and a lack of adjustment for other negative emotions that predict incident CHD. To our knowledge, this is the first study to examine the association between anger expression and CHD using clinically assessed, distinct anger expression styles, while adjusting for depressive symptom, hostility, and anxiety levels.

Our finding that constructive anger is only protective in men is consistent with the results of a recent meta-analysis7 and various studies of anger and CHD. Eng and others2 found that compared to those with low anger expression, men who reported moderately increased levels of anger expression were protected from both incident CHD and stroke. In the Multiple Risk Factor Intervention Trial, Matthews and others 31 conducted a structured interview and used a coded measure similar to the one reported herein and also found that destructive expressions of hostility was associated with an increased risk of cardiovascular mortality. Finally, Chang and others ${ }^{3}$ found that men who expressed destructive anger were at risk for premature CHD. However, these studies only enrolled men. Player and others conducted a secondary analysis of the Atherosclerosis Risk in Communities (ARIC) cohort of men and women ${ }^{32}$ and also found that trait anger predicted incident CHD in men, but not women, at high risk for CHD.

This gender-specific association may be due to the fact that men and women have different ways of expressing anger and hostility.33 While men express anger involving cynicism, women's anger and hostility involve aspects of neuroticism, a construct that has been found to have no increased risk of incident CHD. ${ }^{34}$ Therefore, constructive anger may reflect different socialization of anger expression for men and women. For instance, in our sensitivity analyses, there were gender differences in the association between Constructive anger and depression, hostility and anxiety ( $\mathrm{p}$ for interaction $=0.03,<0.001,0.03$ respectively). The inverse association between Constructive anger and hostility was stronger for men, whereas the inverse 
association between Constructive anger and anxiety and Constructive anger and depression was stronger in women (data not shown). These speculations would need to be tested in future studies, where the reinforcement patterns and personality correlates of these anger expression dimensions can be examined in greater detail.

There are limitations to our study that warrant discussion. Anger expression was measured at baseline, so we cannot examine whether changes in anger expression influence cardiovascular health. Since all covariates were assessed only at baseline, we cannot examine these as timevarying covariates. Because this is a prospective study, residual and unmeasured confounding cannot be ruled out as an alternative explanation of our findings. Finally, it is technically possible that someone received a CHD diagnosis, either before the baseline visit or during the 10 years of surveillance, in an outpatient clinic, and our hospital discharge coding would not have captured this outpatient diagnosis. However, this remains an unlikely possibility, as most incident ischemic heart disease requires in-hospital treatment. This study has many strengths, including a large sample size, comprehensive follow-up, statistical adjustment for other psychosocial measures and an objective, standardized, replicable assessment of different types of anger expression.

Anger expression may represent a modifiable cardiovascular risk factor that could be addressed in primary prevention, but it is important to identify the types of anger that increase and decrease risk so that targeted interventions can be designed. We employed a standardized, clinical assessment to avoid the demand characteristics implicit in asking participants about their motivation for expressing their anger. However, the types of anger expression we assessed are relatively easy to judge in a clinical situation. When a patient expresses anger, are they justifying their anger, or attempting to resolve the situation? Assessment of anger expression type in clinical encounters has not yet been tested for its viability, but may complement evaluations for CHD risk that only assess negative emotions such as depression.

It might be advantageous to teach men to use constructive anger and to teach men and women to decrease discussions of anger that are motivated by the desire to justify or rationalize their emotions. These two types of anger expression are slightly correlated (8\% shared variance), suggesting that discussing anger may be a general tendency, and that those who discuss with constructive motivation may have a slight tendency to also discuss their anger for destructive reasons. It is possible that shifting motivation for anger discussion should be the target of any intervention.

Preliminary evidence has shown that it is possible to increase constructive anger expression in male patients with $\mathrm{CHD}^{9}$ and that these increases are associated with decreased blood pressure in men and women with hypertension. ${ }^{35,}{ }^{36}$ However, further studies are needed to confirm these findings and to test the efficacy of prevention programs designed to improve protective types of anger expression.

\section{Acknowledgments}

We gratefully acknowledge the coders of these videotapes. Dr. Davidson had full access to all of the data in the study and takes responsibility for the integrity of the data and the accuracy of the data analysis. NHLBI had no role in the design and conduct of the study; collection, management, analysis, and interpretation of the data; and preparation, review, or approval of the manuscript.

Funding/Support: This work was supported by grants HL80665, HL-76857, HL-84034, HL088117, and HL072866 from the National Heart, Lung, and Blood Institute, Bethesda, MD. The National Health and Welfare of Canada, Ottawa, Ontario; the Nova Scotia Department of Health, Halifax; and the Heart and Stroke Foundation of New Brunswick, Saint John, supported the original data collection. The project described was also supported by grant UL1 RR024156 from the National Center for Research Resources, Bethesda. 


\section{REFERENCES}

1. Suls J, Bunde J. Anger, anxiety, and depression as risk factors for cardiovascular disease: the problems and implications of overlapping affective dispositions. Psychological Bulletin 2005;131(2):260-300. [PubMed: 15740422]

2. Eng PM, Fitzmaurice G, Kubzansky LD, Rimm EB, Kawachi I. Anger expression and risk of stroke and coronary heart disease among male health professionals. Psychosomatic Medicine 2003;65(1): 100-110. [PubMed: 12554821]

3. Chang PP, Ford DE, Meoni LA, Wang NY, Klag MJ. Anger in young men and subsequent premature cardiovascular disease: The Precursors study. Archives of Internal Medicine 2002;162(8):901-906. [PubMed: 11966341]

4. Eaker ED, Sullivan LM, Kelly-Hayes M, D’Agostino RB Sr, Benjamin EJ. Anger and hostility predict the development of atrial fibrillation in men in the Framingham Offspring study. Circulation 2004;109 (10):1267-1271. [PubMed: 14993133]

5. Myrtek M. Meta-analyses of prospective studies on coronary heart disease, type A personality, and hostility. International Journal of Cardiology 2001;79(23):245-51. [PubMed: 11461748]

6. Schulman JK, Stromberg S. On the value of doing nothing: anger and cardiovascular disease in clinical practice. Cardiol Rev 2007;15(3):123-32. [PubMed: 17438378]

7. Chida Y, Steptoe A. The association of anger and hostility With future Coronary Heart Disease: A meta-analytic review of prospective evidence. Journal of the American College of Cardiology 2009;53 (11):936-946. [PubMed: 19281923]

8. Davidson KW, MacGregor MW, Stuhr J, Dixon K, MacLean D. Constructive anger verbal behavior predicts blood pressure in a population-based sample. Health Psychology 2000;19(1):55-64. [PubMed: 10711588]

9. Gidron Y, Davidson KW, Bata I. The short-term effects of a hostility-reduction intervention on male coronary heart disease patients. Health Psychology 1999;18(4):416-20. [PubMed: 10431944]

10. MacLean, D.; Scott, J.; Beanlands, H.; Hood, R.; Cogdon, A.; LeBlanc, B., et al. The 1995 Nova Scotia Health Survey. Department of Health; Halifax, Nova Scotia: 1996.

11. World Health Organization. International Classification of Diseases, Ninth Revision (ICD-9). Geneva, Switzerland: World Health Organization; 1977.

12. World Health Organization. International Statistical Classification of Diseases, 10th Revision (ICD-10). Geneva, Switzerland: World Health Organization; 1992.

13. Lawson, BJ. Evaluation of non-response bias in the Nova Scotia Health Survey 1995. Dalhousie University; Halifax, Nova Scotia, Canada: 1999.

14. Hall, P.; Davidson, KW.; MacGregor, MW.; MacLean, D. Expanded Structured Interview administration manual: Nova Scotia Health Survey 1995 (NSHS-95). Dalhousie University, Heart Health Nova Scotia; Halifax, Nova Scotia: 1996. Report No.: 1

15. Rowan PJ, Haas D, Campbell JA, Maclean DR, Davidson KW. Depressive symptoms have an independent, gradient risk for coronary heart disease incidence in a random, population-based sample. Annals of Epidemiology 2005;15(4):316-20. [PubMed: 15780780]

16. Wilson PW, D' Agostino RB, Levy D, Belanger AM, Silbershatz H, Kannel WB. Prediction of coronary heart disease using risk factor categories. Circulation 1998;97(18):1837-47. [PubMed: 9603539]

17. Connelly PW, MacLean DR, Horlick L, O’Connor B, Petrasovits A, Little JA. Plasma lipids and lipoproteins and the prevalence of risk for coronary heart disease in Canadian adults. Canadian Heart Health Surveys Research Group. CMAJ 1992;146(11):1977-87. [PubMed: 1596847]

18. Friedewald WT, Levy RI, Fredrickson DS, Friedewald WT, Levy RI, Fredrickson DS. Estimation of the concentration of low-density lipoprotein cholesterol in plasma, without use of the preparative ultracentrifuge. Clinical Chemistry 1972;18(6):499-502. [PubMed: 4337382]

19. Radloff LS. The CES-D Scale: A self-report depression scale for research in the general population. Applied Psychological Measurement 1977;1(3):385-401.

20. Spielberger, C.; Gorusch, R.; Luschene, R. Manual for the State-Trait anxiety inventory. Consulting Psychologists Press; Palo Alto: 1970. 
21. Yan LL, Liu K, Matthews KA, Daviglus ML, Ferguson TF, Kiefe CI. Psychosocial factors and risk of hypertension: the Coronary Artery Risk Development in Young Adults (CARDIA) study. JAMA 2003;290(16):2138-48. [PubMed: 14570949]

22. Iribarren C, Sidney S, Bild DE, Liu K, Markovitz JH, Roseman JM, et al. Association of hostility with coronary artery calcification in young adults: the CARDIA study. Coronary Artery Risk Development in Young Adults. JAMA 2000;283(19):2546-51. [PubMed: 10815118]

23. Barefoot JC, Dodge KA, Peterson BL, Dahlstrom WG, Williams RB Jr. The Cook-Medley hostility scale: item content and ability to predict survival. Psychosomatic Medicine 1989;51(1):46-57. [PubMed: 2928460]

24. McFadyen, M.; McFadyen, S.; MacGregor, MW.; Davidson, KW.; Chambers, L.; MacLean, D. Coding constructive anger from the Expanded Structured Interview: A training Manual (Tech. Rep. No. 3). Dalhousie University, Heart Health Nova Scotia; Halifax, Nova Scotia: 1998.

25. Novaco RW. The functions and regulation of the arousal of anger. Am J Psychiatry 1976;133(10): 1124-8. [PubMed: 788528]

26. Williams, R.; Williams, V. Anger kills: Seventeen strategies for controlling the hostility that can harm your health. Times Books; New York: 1993.

27. Rusting CL, Nolen-Hoeksema S. Regulating responses to anger: effects of rumination and distraction on angry mood. J Pers Soc Psychol 1998;74(3):790-803. [PubMed: 9523420]

28. Manga P, Broyles RW, Angus DE. The determinants of hospital utilization under a universal public insurance program in Canada. Medical Care 1987;25(7):658-70. [PubMed: 3695668]

29. Schafer, JL. Analysis of Incomplete Multivariate Data. CRC Press; Boca Raton: 1997.

30. Nunnally, JC. Psychometric theory. 2 ed. McGraw-Hill; New York: 1978.

31. Matthews KA, Gump BB, Harris KF, Haney TL, Barefoot JC. Hostile behaviors predict cardiovascular mortality among men enrolled in the Multiple Risk Factor Intervention Trial. Circulation 2004;109(1):66-70. [PubMed: 14662707]

32. Player MS, King DE, Mainous AG 3rd, Geesey ME. Psychosocial factors and progression from prehypertension to hypertension or coronary heart disease. Ann Fam Med 2007;5(5):403-11. [PubMed: 17893381]

33. Davidson K, Hall P. What does potential for hostility measure? Gender differences in the expression of hostility. Journal of Behavioral Medicine 1995;18(3):233-47. [PubMed: 7674290]

34. Watson D, Pennebaker JW. Health complaints, stress, and distress: exploring the central role of negative affectivity. Psychol Rev 1989;96(2):234-54. [PubMed: 2710874]

35. Davidson KW, MacGregor MW, Stuhr J, Gidron Y. Increasing constructive anger verbal behavior decreases resting blood pressure: A secondary analysis of a randomized controlled hostility intervention. International Journal of Behavioral Medicine 1999;6(3):268-278. [PubMed: 16250680]

36. Trudeau, KJ.; E., M.; Stuhr, J.; Davidson, KW. CONSORT Explanation of the CONSORT Statement with application to psychosocial interventions. In: Nezu, AM.; Nezu, CM., editors. Evidence-based outcome research: A practical guide to conducting randomized clinical trials for psychosocial interventions. Oxford Publishers; Washington: 2007. p. 25-44.

37. Frasure-Smith N, Lesperance F, Talajic M. The impact of negative emotions on prognosis following myocardial infarction: is it more than depression? Health Psych 1995;14(5):388-98.

38. Williams JE, Nieto FJ, Sanford CP, Tyroler HA. Effects of an angry temperament on coronary heart disease risk : The Atherosclerosis Risk in Communities Study. Am J Epi 2001;154(3):230-5.

39. Frasure-Smith N, Lesperance F. Depression and other psychological risks following myocardial infarction. Archives of General Psychiatry 2003;60(6):627-36. [PubMed: 12796226]

40. Shen BJ, Avivi YE, Todaro JF, Spiro A 3rd, Laurenceau JP, Ward KD, et al. Anxiety characteristics independently and prospectively predict myocardial infarction in men the unique contribution of anxiety among psychologic factors. J Am Coll Cardiol 2008;51(2):113-9. [PubMed: 18191733] 


\section{Spielberger Anger-Out Expression Scale}

Frasure-Smith et al, $1995^{37}$ Williams et al, $2001^{38}$

Eng et al, 2003 (men, moderate anger, MI) ${ }^{2}$

Eng et al, 2003 (men, high anger, MI) ${ }^{2}$ Eng et al, 2003 (men, moderate anger, angina) ${ }^{2}$ Eng et al, 2003 (men, high anger, angina) $)^{2}-$ Frasure-Smith et al, 200339Eaker et al, 2004 (men) ${ }^{4}$ Eaker et al, 2004 (women) ${ }^{4}$ -

MMPI-2 Anger Scale Shen et al, 200840 NSHS95

\begin{abstract}
Destructive Anger RuminationDestructive Anger Verbal JustificationConstructive Anger (men)Constructive Anger (women)-
\end{abstract}

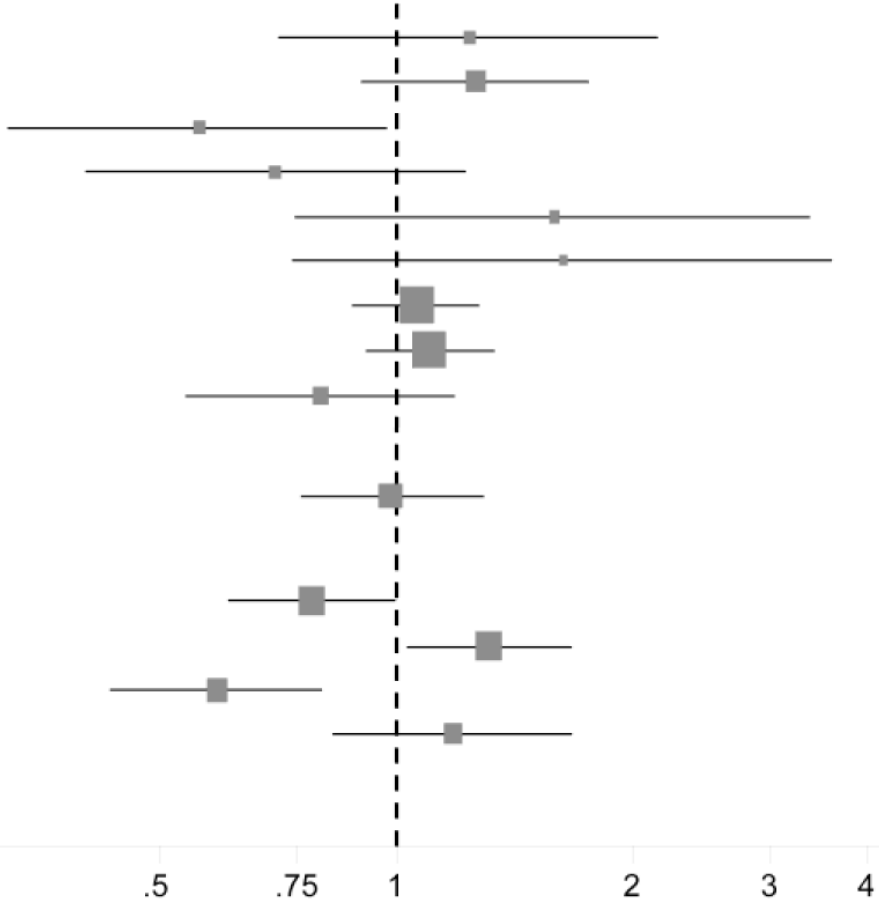

Risk Ratios and 95\% Confidence Interval (log scale)

Figure 1.

Protective and Harmful Aspects of Anger Expression

Dashed line indicates null value

Size of square indicates the inverse variance weight 


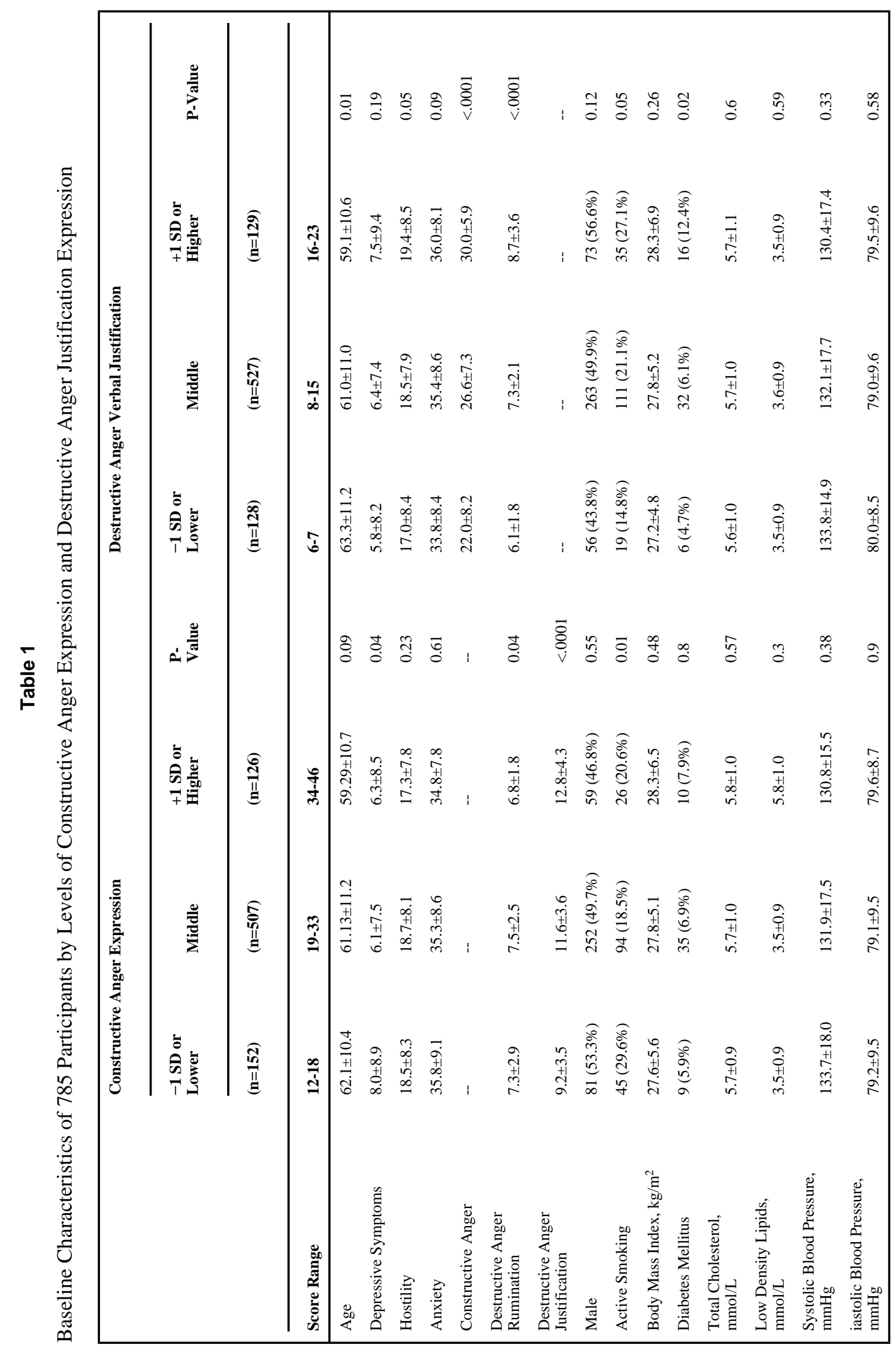

Am Heart J. Author manuscript; available in PMC 2011 February 1. 
Table 2

Characteristics of the NSHS95 Measures

\begin{tabular}{|l|c|c|c|c|}
\hline Construct & $\begin{array}{c}\text { No. of } \\
\text { Items }\end{array}$ & $\begin{array}{c}\text { Score } \\
\text { Range }\end{array}$ & Mean (SD) Score & Cronbach $\boldsymbol{\alpha}$ \\
\hline Depressive Symptoms & 20 & $0-60$ & $6.53(7.96)$ & .89 \\
\hline Hostility & 50 & $2-50$ & $18.44(8.13)$ & .87 \\
\hline Anxiety & 20 & $20-64$ & $35.30(8.53)$ & .89 \\
\hline Constructive anger & 12 & $12-46$ & $26.38(7.58)$ & .93 \\
\hline Destructive anger justification & 6 & $6-23$ & $11.32(3.86)$ & .87 \\
\hline Destructive anger rumination & 5 & $5-20$ & $7.32(2.49)$ & .82 \\
\hline
\end{tabular}




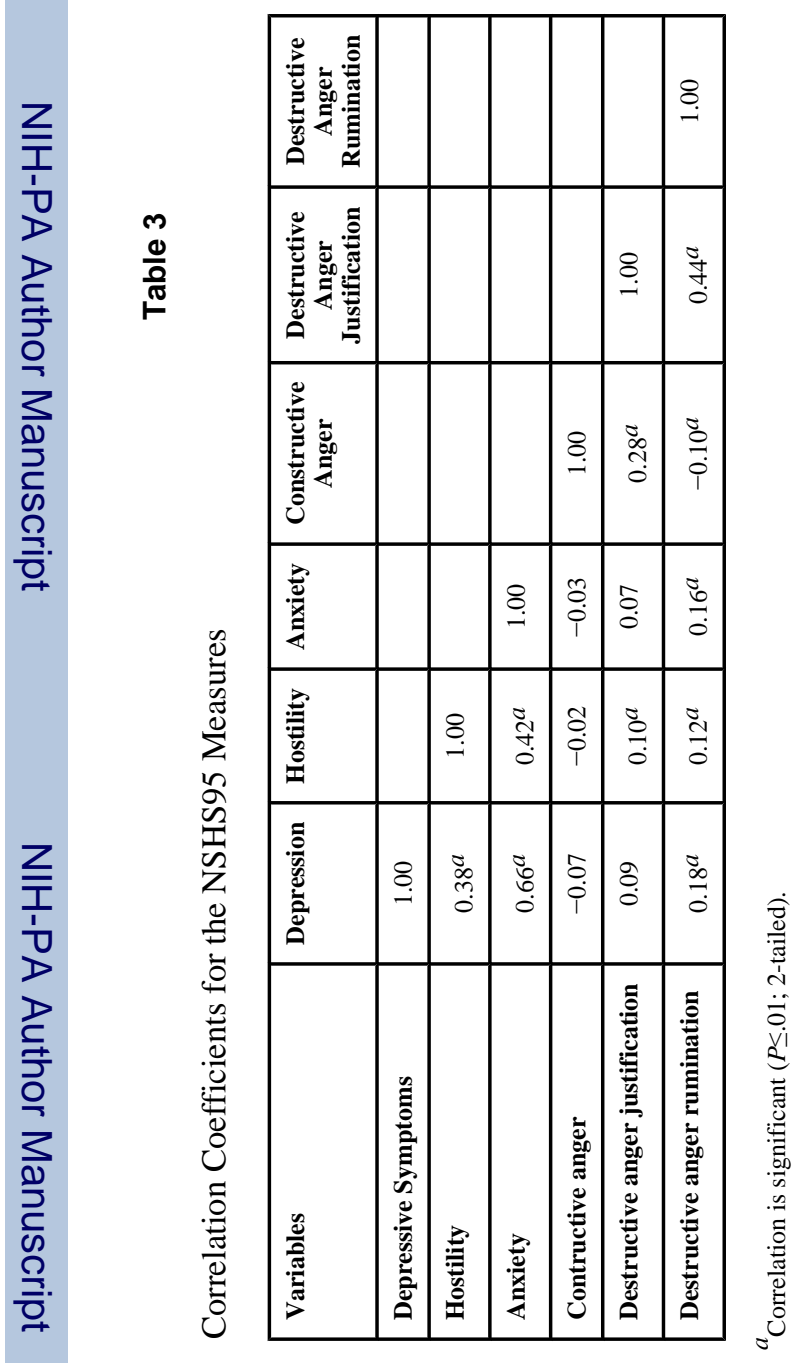

Am Heart J. Author manuscript; available in PMC 2011 February 1. 
Table 4

Hazard Ratios (and 95\% Confidence Intervals) of Incident CHD Events for One Standard Deviation Increase in Exposure

\begin{tabular}{|l|c|c|c|}
\hline \multirow{2}{*}{ Predictor } & \multirow{2}{*}{$\begin{array}{c}\text { Score Associated } \\
\text { With a 1-SD Increase } \\
\text { in Exposure }\end{array}$} & \multicolumn{2}{|c|}{ Hazard Rate (95\% CI) } \\
\cline { 3 - 4 } & 7.96 & Model 1 & Model 2 \\
\hline Depressive Symptoms & 8.13 & $1.26(\mathbf{1 . 0 5}-1.50)$ & $\mathbf{1 . 3 9}(\mathbf{1 . 0 9 - 1 . 7 8})$ \\
\hline Hostility & 8.53 & $1.05(0.86-1.27)$ & $0.79(0.60-1.04)$ \\
\hline Anxiety & 7.58 & $\ldots$ & $\ldots$ \\
\hline Constructive anger & $\ldots$ & $\mathbf{0 . 7 0}(\mathbf{0 5 4 - 0 . 9 3})$ & $\mathbf{0 . 5 9}(\mathbf{0 . 4 3 - 0 . 8 0})$ \\
\hline Men & $\ldots$ & $1.18(0.85-1.63)$ & $1.18(0.83-1.68)$ \\
\hline Women & 3.86 & $1.16(0.95-1.41)$ & $\mathbf{1 . 3 1}(\mathbf{1 . 0 3}-1.67)$ \\
\hline Destructive anger justification & 2.49 & $0.97(0.81-1.17)$ & $0.82(0.66-1.02)$ \\
\hline Destructive anger rumination & & &
\end{tabular}

Abbreviation: CHD indicates coronary heart disease; CI, confidence interval.

${ }^{a}$ In model 1, we adjusted for age at baseline (continuous), sex, smoking (smoking actively or within the past year vs. all others), history of diabetes mellitus (yes/no), body mass index $\left(\mathrm{kg} / \mathrm{m}^{2}\right)$, total cholesterol ( $\left.\mathrm{mmol} / \mathrm{L}\right)$, low-density lipoprotein $(\mathrm{mmol} / \mathrm{L})$, systolic blood pressure ( $\mathrm{mm} \mathrm{Hg}$ ), and diastolic blood pressure ( $\mathrm{mm} \mathrm{Hg}$ ), measured as continuous terms. Model 2 is further adjusted for the 6 psychosocial predictors listed (continuous variables). Baseline rates were allowed to vary by region. Ellipses indicate not applicable. Bold indicates significant at $P<.05$. 